\title{
Fifteen years of no till increase soil organic matter, microbial biomass and arthropod diversity in cover crop-based arable cropping systems
}

\author{
Tek Bahadur Sapkota $\cdot$ Marco Mazzoncini • \\ Paolo Bàrberi • Daniele Antichi • Nicola Silvestri
}

Accepted: 19 December 2011 / Published online: 11 January 2012

(C) INRA and Springer-Verlag, France 2011

\begin{abstract}
The physical, chemical and biological properties of soil may be modified by tillage, fertilization and cover crops. However there is little knowledge on long-term effects on soil properties, notably under Mediterranean climate. Moreover, biological indicators such as micro-arthropods can be used for a cost-effective analysis of soil biodiversity. Here, we studied physical and biological properties of a sandy loam soil in central Italy under a 4-year rotation of maize-durum wheat-cover crop-sunflower-durum wheat-cover crop during 15 years. We analysed the effects of two tillage systems, conventional tillage (CT) and no-tillage (NT); two N fertilization rates, without $\mathrm{N}$ and medium $\mathrm{N}$ level; and three soil covers: cash crop residue as control, Brassica juncea and Vicia villosa. Results show that no tillage increased soil organic matter content in the upper $10-\mathrm{cm}$ layer $(3.31 \%)$ compared to the conventional tillage (2.19\%). No tillage also improved structure stability and lowered bulk density in the same soil profile. No-tillage systems showed higher soil microbial biomass ( $+71 \%)$ and respiration $(+44 \%)$, and a higher abundance and diversity of micro-arthropods. We conclude that no tillage
\end{abstract}

\author{
T. B. Sapkota $\cdot$ P. Bàrberi \\ Institute of Life Sciences, Scuola Superiore Sant'Anna, \\ Piazza Martiri della Libertà 33, \\ 56127 Pisa, Italy \\ M. Mazzoncini $(\square)$ \\ Interdepartmental Center for Agro-Environmental \\ Research 'E. Avanzi', \\ Via Vecchia di Marina 6, San Piero a Grado, \\ 56122 Pisa, Italy \\ e-mail: mazzo@agr.unipi.it \\ D. Antichi • N. Silvestri \\ Department of Agronomy and Agro-ecosystem Management, \\ University of Pisa, \\ Via San Michele degli Scalzi, 2, \\ 56124 Pisa, Italy
}

is an effective measure to improve the physical and biological quality of soil in Mediterranean conditions. No-tillage positive effect can be enhanced by the right choice of $\mathrm{N}$ fertilization and cover crop cultivation. Bio-indicators such as microarthropods can be very predictive of soil habitability by organisms.

Keywords Soil organic matter- Aggregate stability . Microbial biomass carbon $\cdot$ Micro-arthropod diversity $\cdot$ Soil biological quality

\section{Introduction}

Tillage, nitrogen fertilization and cover crop cultivation are some of the most important management practices that affect many physical, chemical and biological characteristics of the soil. These practices can all affect soil carbon concentration (C) either directly, i.e. by increasing crop productivity and the amount of $\mathrm{C}$ potentially returning to the soil as crop residues, or indirectly by changing the mineralization rate of the soil organic matter. This is due to the effects on different soil characteristics such as humidity, oxygen levels and microbial activity (Lal 2004).

No-tillage systems, for instance, increase soil organic matter by reducing mineralization rates and stimulating litter concentrations (i.e. crop residues, weeds, mulches) in the shallow soil (Alvarez and Steinbach, 2009). Nitrogen fertilization can improve soil $\mathrm{C}$ due to increased crop residues incorporated into the soil, it also contributes to a wellbalanced C/N ratio (Malhi and Lemke, 2007). Cover crops have also been shown to offer many benefits to soil fertility and crop production (Dabney et al., 2001), as they can: (1) increase organic matter content by producing a huge amount of biomass that is incorporated into the soil; (2) increase the $\mathrm{N}$ 
and $\mathrm{P}$ availability by stimulation of nutrients cycling or by symbiotic fixation of atmospheric $\mathrm{N}_{2}$ (legume crops); (3) decrease nutrient losses (e.g. by the uptake of exceeding nitrates); (4) reduce soil erosion and organic matter mineralization during otherwise fallow periods.

However, tillage, cover cropping and $\mathrm{N}$ fertilization interact in a complex way to affect the physical, chemical and biological properties of the soil. Thus, their real effect on soil fertility and on the sustainability of cropping systems will depend more on their agronomical consistency rather than the sum of their individual effects. This is particularly true for external lowinput cropping systems, which aim to maximize all the benefits from the exploitation of the natural resources of agroecosystems (Silvestri and Bellocchi, 2007). For example, legume cover crops have been demonstrated to enrich soil $\mathrm{N}$ and may therefore reduce the amount of $\mathrm{N}$ fertilizers needed for the succeeding crop. This effect, however, may change with different tillage practices due to their different influences on residue decomposition, leading to different rates of soil nutrient mineralization (Cambardella and Elliott, 1993).

In order to assess the effects of complex agronomic strategies on soil properties, several physical, chemical and biological indicators need to be monitored. An overall examination of these indicators can then be used to describe in great detail the effects of agricultural techniques on soil functionality. To save time and resources, the most recent soil quality assessment methods have been aimed at identifying new key indicators that may be put together with the most common ones (e.g. soil organic matter content, structure stability and bulk density), in order to summarize the remaining unexplored information.

Great attention has been recently given to the biological monitoring of micro-arthropods, which are recognized as good indicators of soil quality. This is due to the high sensitivity of these organisms to land management practices that affect the habitability of edaphic environments, and to their essential role in organic matter accumulation and nutrient cycling (De Goede and Brussaard 2002). Furthermore, they are relatively easy to assess and inexpensive to replicate in space and time, since they are mainly concentrated in the upper soil layers (Parisi et al., 2005).

In order to investigate the combined effect of tillage, $\mathrm{N}$ fertilization and cover crops, we monitored selected soil properties and the presence of soil micro-arthropods in a long-term field experiment that started in 1993.

\section{Materials and methods}

\subsection{Treatments and experimental design}

The long-term field experiment was set up in 1993 at the Interdepartmental Center for Agro-environmental Research
(Centro Interdipartimentale di Ricerche Agro-Ambientali 'Enrico Avanzi') of the University of Pisa, Central Italy (Lat. $43^{\circ} 40^{\prime} \mathrm{N}$; Long. $10^{\circ} 19^{\prime} \mathrm{E}$ ). Climatic conditions are representative of Mediterranean coastal areas, with a yearly average rainfall and temperature of $826 \mathrm{~mm}$ and $15^{\circ} \mathrm{C}$, respectively.

The experimental site has a Typic Xerofluvent loam soil (443, 402 and 155 g.1,000 $\mathrm{g}^{-1}$ of sand, silt and clay, respectively). At the beginning of the experiment in the $0-30 \mathrm{~cm}$ layer, the soil $\mathrm{pH}$ was 8.2 and the organic matter content was $1.82 \%$ (Walkey and Black method). Total $\mathrm{N}$ and assimilable $\mathrm{P}$ concentrations were $0.13 \%$ and $24 \mathrm{mg} \mathrm{kg}^{-1}$, respectively (Khjeldahl and Olsen methods). There were no preliminary data on the physical and biological characteristics of the soil; therefore it was not possible to compare the parameters over time.

This long-term experiment combines two tillage systems, four $\mathrm{N}$ fertilization rates and four soil cover types in a splitsplit-plot design with four replications, with tillage systems in the main plots, nitrogen rates in the sub-plots and cover crops in the sub-sub-plots (Mazzoncini et al., 2011). Altogether, there are 128 sub-sub-plots, $21 \mathrm{~m}$ long and $11 \mathrm{~m}$ wide (approximately $230 \mathrm{~m}^{2}$ ).

The tillage systems are conventional tillage (CT) with ploughing of the cover crops down to $30 \mathrm{~cm}$ depth, and notillage (NT) with surface mulching of cover crops. The four nitrogen fertilization rates range from null to low, medium and high levels depending on the main crops in the rotation. The soil cover types consist of three different cover crop species (Vicia villosa Roth, Trifolium squarrosum L., Brassica juncea L.) and a cash crop residue as a control.

Of all the possible combinations of treatments, we selected those characterized by the strongest contrast from an agronomic point of view and the most representative in terms of the usual farming management in Central Italy. We focused on two tillage systems, two $\mathrm{N}$ fertilization rates (null and medium) and three cover types, i.e. $V$. villosa, $B$. juncea and the control, in order to analyse the physical and chemical parameters. With regard to microbiological properties, only two cover crop types ( $V$. villosa and control) were considered along with the two tillage systems and two $\mathrm{N}$ rates (null and medium), whereas for the biological indicators, only two tillage systems and three cover types ( $V$. villosa, $B$. juncea and control) were considered, assuming a medium $\mathrm{N}$ rate as a standard fertilization rate.

\subsection{Crop management}

The crop management was modified throughout the course of the study to fit the environmental and agronomical changes in the sustainability paradigms. Grain maize (Zea mays L.) was cultivated as a continuous crop from 1993 to 1998. The cropping system was then changed to a 2-year 
crop rotation of maize and durum wheat (Triticum durum Desf.). Since 2005, the following 4-year crop rotation has been adopted: maize - durum wheat - sunflower (Helianthus annuus L.) - durum wheat. The cover crops are sown in early autumn after the wheat, and terminated before the maize and sunflower planting. In the CT system, cover crops are incorporated into the soil with a mouldboard plough to a depth of 30-35 cm after mechanical killing by disk harrow or shredder. In the NT system, on the other hand, they are desiccated with glyphosate and retained on the soil surface as dead mulch.

All plots were fertilized before sowing the main crop with $46 \mathrm{~kg} \mathrm{ha}^{-1} \mathrm{P}_{2} \mathrm{O}_{5}$ (as superphosphate) and $50 \mathrm{~kg} \mathrm{ha}^{-1} \mathrm{~K}_{2} \mathrm{O}$ (as potassium sulphate). $\mathrm{N}$ fertilizer was applied to the main crops according to the treatment rates (respectively 0, 100, 200 and $300 \mathrm{~kg} \mathrm{Nha}^{-1}$ for maize; $0,60,120$ and $180 \mathrm{~kg} \mathrm{Nha}^{-1}$ for durum wheat; and $0,50,100$ and $150 \mathrm{~kg} \mathrm{Nha}^{-1}$ for sunflower) either as just one or as two separate applications at the rate of $50 \%$ each.

For further details on crop management see Mazzoncini et al. (2011).

\subsection{Soil sampling and laboratory analysis}

The soil properties examined were as follows: (i) physical and chemical: aggregate stability index, organic matter content and bulk density; (ii) microbiological: microbial biomass, microbial respiration, metabolic quotient and microbial quotient; (iii) biological: diversity, richness, evenness and quality of micro-arthropod community.

Soil sampling and analyses were carried out in 2008 when, in accordance with the cropping system design, all plots were planted with sunflower. For all the analyses, two soil subsamples were taken from each plot, the results of which were averaged to get the plot value. For the bulk density analysis, a steel probe with a metal cylinder $\left(22.3 \mathrm{~cm}^{3}\right)$ inside was used to take samples from three different depths, i.e. 0-10, 10-20 and 20-30 cm. The soil samples were collected at the end of spring, weighed immediately after sampling and then after oven drying $\left(105^{\circ} \mathrm{C}\right.$ for $\left.24 \mathrm{~h}\right)$.

Soil bulk density was calculated as the ratio between the weight of oven-dried soil and the bulk volume of the soil (Hao et al., 2006). A gauge shovel was used to take soil samples to determine the soil aggregate stability index, soil organic matter content, microbial biomass $\mathrm{C}$ content and soil microbial respiration. The soil aggregate stability index and organic matter content were determined in the $0-5$ and $5-10 \mathrm{~cm}$ soil depths. Soil samples were air dried, ground and sieved through a $2 \mathrm{~mm}$ mesh. The percentage of stable macro-aggregate ( $<2 \mathrm{~mm}$ in diameter) was determined following the wet aggregate stability method (Kemper and Rosenau, 1986) by using a $0.25 \mathrm{~mm}$ sieve. The soil aggregate stability index (SASI) was calculated as:

$S A S I=\left[1-\left(\frac{A}{B}\right)\right] \times 100$

where A and B are the weights of aggregates passed through the sieve after 5 and $60 \mathrm{~min}$, respectively (Pagliai et al., 1997). Organic matter content was determined by the acid oxidation method (Nelson and Sommers, 1982).

Soil microbial biomass, expressed as microbial $\mathrm{C}$ per mass unit of soil, and soil microbial respiration, expressed as $\mathrm{CO}_{2}$ produced per mass unit of soil, were determined in the 0 $10 \mathrm{~cm}$ soil depth. Moist field soil samples were sieved through a $2 \mathrm{~mm}$ mesh, and immediately stored in sealed plastic bags at $4^{\circ} \mathrm{C}$. The samples were adjusted to $60 \%$ of the field capacity. Microbial C was estimated by the fumigation-extraction method (Vance et al., 1987), while microbial respiration was estimated by measuring the $\mathrm{CO}_{2}$ evolution using the closed jar method (Alef, 1995).

The metabolic quotient expresses the units of $\mathrm{CO}_{2}$ respired per unit of microbial biomass and was calculated as the ratio between soil microbial respiration $\left(\mu \mathrm{g} \mathrm{CO}_{2}-\mathrm{C} \mathrm{g}^{-1}\right.$ of dry soil $\left.\mathrm{h}^{-1}\right)$ and soil microbial biomass $\mathrm{C}\left(\mu \mathrm{g} \mathrm{Cg}^{-1}\right.$ of dry soil). The microbial quotient was calculated as the ratio of soil microbial biomass $\mathrm{C}$ and soil organic $\mathrm{C}$. Both metabolic and microbial quotients were calculated individually for each sample and mean values were then determined.

To collect micro-arthropods, two soil blocks $(10 \times 5 \times$ $10 \mathrm{~cm}$ depth) were taken randomly from each plot. The soil blocks were then kept in a plastic bag to make a composite sample. The soil samples were taken to the laboratory as undisturbed as possible. They were then put in a Berlese-

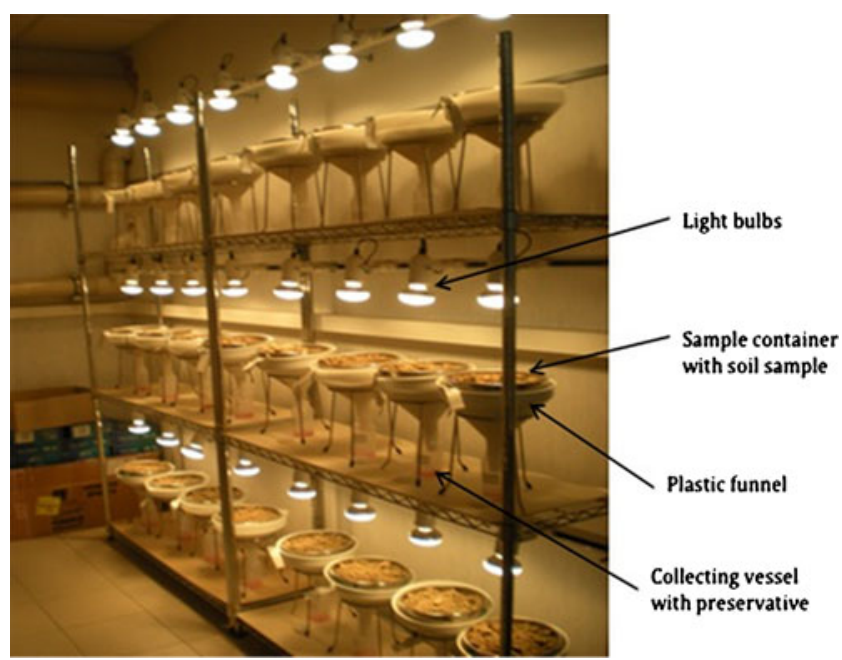

Fig. 1 Berlese-Tullgren funnel for micro-arthropods extraction. It contains a sample container with wire mesh, a plastic funnel over which the sample container is placed and a collecting vessel below the funnel which contains a liquid preservative 
Tullgren funnel (Figure 1), where they were kept for 8 days. As a source of heat and desiccation, light bulbs were placed above the sample. To escape from light and heat, microarthropods moved downwards and were collected in a preservative solution (two parts $75 \%$ ethanol and one part glycerol) in the collecting vessel below. The collected specimens were observed under a stereomicroscope for microarthropod identification.

\subsection{Calculation of the micro-arthropod parameters}

Simpson's diversity index, group richness and evenness were calculated from the total number of micro-arthropods belonging to each group. Simpson's index, a simple mathematical measure that characterizes species diversity in a community, was used as it provides a good estimate of diversity in a relatively small sample size (Magurran, 2004). The total number of micro-arthropod groups found in the sample was considered as group richness. Simpson's diversity index (D) was calculated as:

$\mathrm{D}=\frac{1}{\sum_{i=1}^{n} p i^{2}}$

where, $\mathrm{p}_{i}$ represents the number of individuals in $\mathrm{i}^{\text {th }}$ group relative to the total number of individuals found in a given sample.

The evenness (ED) of the group distribution was calculated as the proportion of $\mathrm{D}$ value for each group to the maximum value of D (Dmax), i.e.:

$\mathrm{E}_{\mathrm{D}}=\frac{\mathrm{D}}{\mathrm{D}_{\mathrm{mac}}}$

D has a maximum value (Dmax) when individuals in the community are perfectly evenly distributed. We considered the total number of groups in a sample as Dmax, which also corresponds to group richness. This is because Dmax is always equal to the number of species when species are completely evenly distributed.

The biological soil quality (BSQ) index, which was originally developed as Qualità Biologica del Suolo (Parisi et al., 2005), is a good example of an integrated and easy-to-use method to include the composition of the micro-arthropod community in a soil quality assessment. This method is based on the concept that the higher the quality of the soil, the higher the number of micro-arthropod groups well adapted to soil habitats.

Following the BSQ approach, each group of microarthropods found in the soil sample was given a score (called Eco-Morphological Index, EMI) from 1 to 20, based on its adaptation to the soil environment (Parisi et al. 2005). As a general rule, eu-edaphic (i.e. deep soil-living) forms get a score of 20, hemi-edaphic (i.e. intermediate) forms are given an index rating proportionate to their degree of specialization, while epi-edaphic (surface-living) forms score 1 . The BSQ value of a given plot was calculated as the sum of the EMI values of all the collected groups found in the plot.

\subsection{Data analysis}

Analysis of variance was performed with CoStat Software (CoHort, 2002) after checking for homogeneity of error variances (Bartlett test), which was verified for each studied variable. When treatments and interaction effects were significant, differences between treatment means were compared using LSD (Gomez and Gomez, 1984).

Non-linear regression analysis was used to describe variation in the soil aggregate stability index as a function of soil organic matter changes in the soil.

\section{Results and discussion}

\subsection{Soil physical and chemical parameters}

The tillage system, $\mathrm{N}$ fertilization level and cover crops significantly affected soil aggregate stability in both soil depths studied (Table 1). The NT system had more than a three and four fold higher aggregate stability index than the CT system at $0-5 \mathrm{~cm}$ and 5-10 $\mathrm{cm}$ depths, respectively (Table 2). On average, the soil aggregate stability index was approximately $80 \%$ higher in the system with $\mathrm{N}$ fertilization than in the system without $\mathrm{N}$ fertilization (Table 2). The system planted with the $V$. villosa cover crop had a significantly higher soil aggregate stability index than that planted with the $B$. juncea cover crop $(+62 \%)$ and that without the cover crop $(+72 \%)$, whilst the latter two were not statistically different.

Improvements in soil aggregate stability in conservation tillage including legume cover crops have also been reported by Kladivko et al. (1986). In contrast, regular cultivation of soil in the CT system results in disruption of the soil aggregates (Tisdall and Oades, 1982).

The soil aggregate stability index was significantly affected by $\mathrm{N}$ fertilization $\mathrm{x}$ tillage and cover crops $\mathrm{x}$ tillage interactions (Table 1). The system with $\mathrm{N}$ fertilization significantly increased the soil aggregate stability index under NT in both soil depths, whereas the effect of $\mathrm{N}$ fertilization was not significant under the CT system (Figure 2). The beneficial effect of the NT system on soil aggregate stability was also further enhanced by the inclusion of the $V$. villosa cover crop, but was not evident under the CT system (Figure 2).

The positive effect on aggregate stability of the combination of nitrogen fertilization and the $V$. villosa cover crop was not revealed in the ploughing system. In contrast, in the no-tillage plots, the individual treatments kept a favourable 
Table 1 Analysis of variance (ANOVA) of aggregate stability index and soil organic matter content (\%) for three soil cover types (C) over two $\mathrm{N}$ fertilization rates $(\mathrm{N})$ and two tillage systems $(\mathrm{T})$ in 2008 . $* * *, * * *=$ significant at the $0.05,0.01$ and 0.001 probability level, respectively. NS, non significant

\begin{tabular}{|c|c|c|c|c|c|c|c|}
\hline \multirow[b]{2}{*}{ Sources of variation } & \multirow[b]{2}{*}{ df } & \multicolumn{3}{|c|}{ Soil aggregate stability index } & \multicolumn{3}{|c|}{ Soil organic matter $(\%)$} \\
\hline & & $0-5 \mathrm{~cm}$ & $5-10 \mathrm{~cm}$ & $0-10 \mathrm{~cm}$ & $0-5 \mathrm{~cm}$ & $5-10 \mathrm{~cm}$ & $0-10 \mathrm{~cm}$ \\
\hline Tillage $(\mathrm{T})$ & 1 & $* *$ & $*$ & $* * *$ & $* * *$ & $* *$ & $* *$ \\
\hline $\mathrm{N}$ fertilization $(\mathrm{N})$ & 1 & $* *$ & $*$ & $* * *$ & $* *$ & $* *$ & $* *$ \\
\hline $\mathrm{N} \times \mathrm{T}$ & 1 & $* *$ & $* *$ & $* * *$ & $* *$ & $* * *$ & $* * *$ \\
\hline Cover types (C) & 2 & $* *$ & $* * *$ & $* * *$ & $* * *$ & $* * *$ & $* * *$ \\
\hline $\mathrm{C} \times \mathrm{T}$ & 2 & $* *$ & $* * *$ & $* * *$ & $* * *$ & $* * *$ & $* * *$ \\
\hline $\mathrm{C} \times \mathrm{N}$ & 2 & NS & NS & NS & NS & NS & NS \\
\hline $\mathrm{C} \times \mathrm{N} \times \mathrm{T}$ & 2 & NS & NS & $*$ & NS & NS & NS \\
\hline
\end{tabular}

effect on aggregate stability, at least for the interaction of second level ( $\mathrm{N}$ fertilization $\mathrm{x}$ Tillage, and Cover type $\mathrm{x}$ Tillage). This finding highlights the greater importance of consistency in terms of agronomic management choices in conservative agriculture systems than conventional ones. For instance, soil structure stability can be improved under NT simply by applying a $\mathrm{N}$ fertilizer at the medium rate or by growing $V$. villosa cover crop in between the main crop cycles.

The results obtained for soil organic matter content were similar to the results for aggregate stability with regard to both main treatments and interactions.

The effects of tillage on soil organic matter content were significant in both the soil depths studied (Table 1). NT had a higher percentage than the CT and, averaged over soil depth, soil organic matter was approximately $50 \%$ higher in NT than in CT (Table 2).

The effect of $\mathrm{N}$ fertilization was also significant in both soil layers and in the whole $0-10 \mathrm{~cm}$ soil profile (Table 1).
Soil organic matter content was slightly higher in the system with $\mathrm{N}$ fertilization than in the system without (Table 2).

Similarly, cover crop effects were significant in both soil depths (Table 1). The system planted with a leguminous cover crop had a significantly higher soil organic matter content than the system planted with a non-leguminous cover crop and without cover crop (Table 2). On average, the system planted with $V$. villosa had about a $10 \%$ higher soil organic matter content than the other systems.

The interaction effects (i.e. $\mathrm{N}$ fertilization $\mathrm{x}$ Tillage and Cover crops $\mathrm{x}$ Tillage) were significant for soil organic matter in both soil depths and also averaged over soil depths (Table 1). The effect of $\mathrm{N}$ fertilization was not significant in CT but significant for NT in both soil depths (Figure 3). Similarly, under NT, the system planted with $V$. villosa had a significantly higher soil organic matter content than the system planted with $B$. juncea and without cover crop in both soil depths (Figure 3). In the CT system, the effects of
Table 2 Effect of tillage systems, $\mathrm{N}$ fertilization and cover crops on soil aggregate stability index and soil organic matter content at different soil depths (2008). Within each factor, means in the same column followed by different letters are significantly different at $\mathrm{P}<0.05$ (LSD test). ${ }^{\star} \mathrm{CT}$, conventional tillage; $\mathrm{NT}$, no tillage. ${ }^{\S} \mathrm{N} 0=$ no $\mathrm{N}$ fertilization, $\mathrm{N} 2=200$, 120 and $100 \mathrm{~kg} \mathrm{Nha}^{-1}$ for maize, durum wheat and sunflower, respectively. C, no cover crops; BJ, B. juncea; $\mathrm{VV}, V$. villosa

\begin{tabular}{|c|c|c|c|c|c|c|}
\hline \multirow[b]{2}{*}{ Treatments } & \multicolumn{3}{|c|}{ Soil aggregate stability index } & \multicolumn{3}{|c|}{ Soil organic matter $(\%)$} \\
\hline & $0-5 \mathrm{~cm}$ & $5-10 \mathrm{~cm}$ & $0-10 \mathrm{~cm}$ & $0-5 \mathrm{~cm}$ & $5-10 \mathrm{~cm}$ & $0-10 \mathrm{~cm}$ \\
\hline \multicolumn{7}{|l|}{ Tillage } \\
\hline NT & $8.85 \mathrm{a}$ & $7.80 \mathrm{a}$ & $8.33 \mathrm{a}$ & $3.35 \mathrm{a}$ & $3.28 \mathrm{a}$ & $3.31 \mathrm{a}$ \\
\hline $\mathrm{CT}$ & $2.54 \mathrm{~b}$ & $1.79 \mathrm{~b}$ & $2.16 \mathrm{~b}$ & $2.23 \mathrm{~b}$ & $2.14 \mathrm{~b}$ & $2.19 \mathrm{~b}$ \\
\hline \multicolumn{7}{|c|}{$\mathrm{N}$ fertilization ${ }^{\S}$} \\
\hline No & $4.05 \mathrm{~b}$ & $3.35 \mathrm{~b}$ & $3.70 \mathrm{~b}$ & $2.67 \mathrm{~b}$ & $2.60 \mathrm{~b}$ & $2.64 \mathrm{~b}$ \\
\hline $\mathrm{N} 2$ & $7.34 \mathrm{a}$ & $6.24 \mathrm{a}$ & $6.79 \mathrm{a}$ & $2.91 \mathrm{a}$ & $2.82 \mathrm{a}$ & $2.86 \mathrm{a}$ \\
\hline \multicolumn{7}{|c|}{ Cover Crops ${ }^{\pi}$} \\
\hline $\mathrm{C}$ & $5.09 \mathrm{~b}$ & $3.24 \mathrm{~b}$ & $4.16 \mathrm{~b}$ & $2.73 \mathrm{~b}$ & $2.57 \mathrm{~b}$ & $2.65 \mathrm{~b}$ \\
\hline $\mathrm{BJ}$ & $4.29 \mathrm{~b}$ & $4.55 \mathrm{~b}$ & $4.42 \mathrm{~b}$ & $2.65 \mathrm{~b}$ & $2.63 \mathrm{~b}$ & $2.64 \mathrm{~b}$ \\
\hline VV & $7.71 \mathrm{a}$ & $6.61 \mathrm{a}$ & $7.16 \mathrm{a}$ & $3.00 \mathrm{a}$ & $2.93 \mathrm{a}$ & $2.96 \mathrm{a}$ \\
\hline
\end{tabular}




\section{SASI}
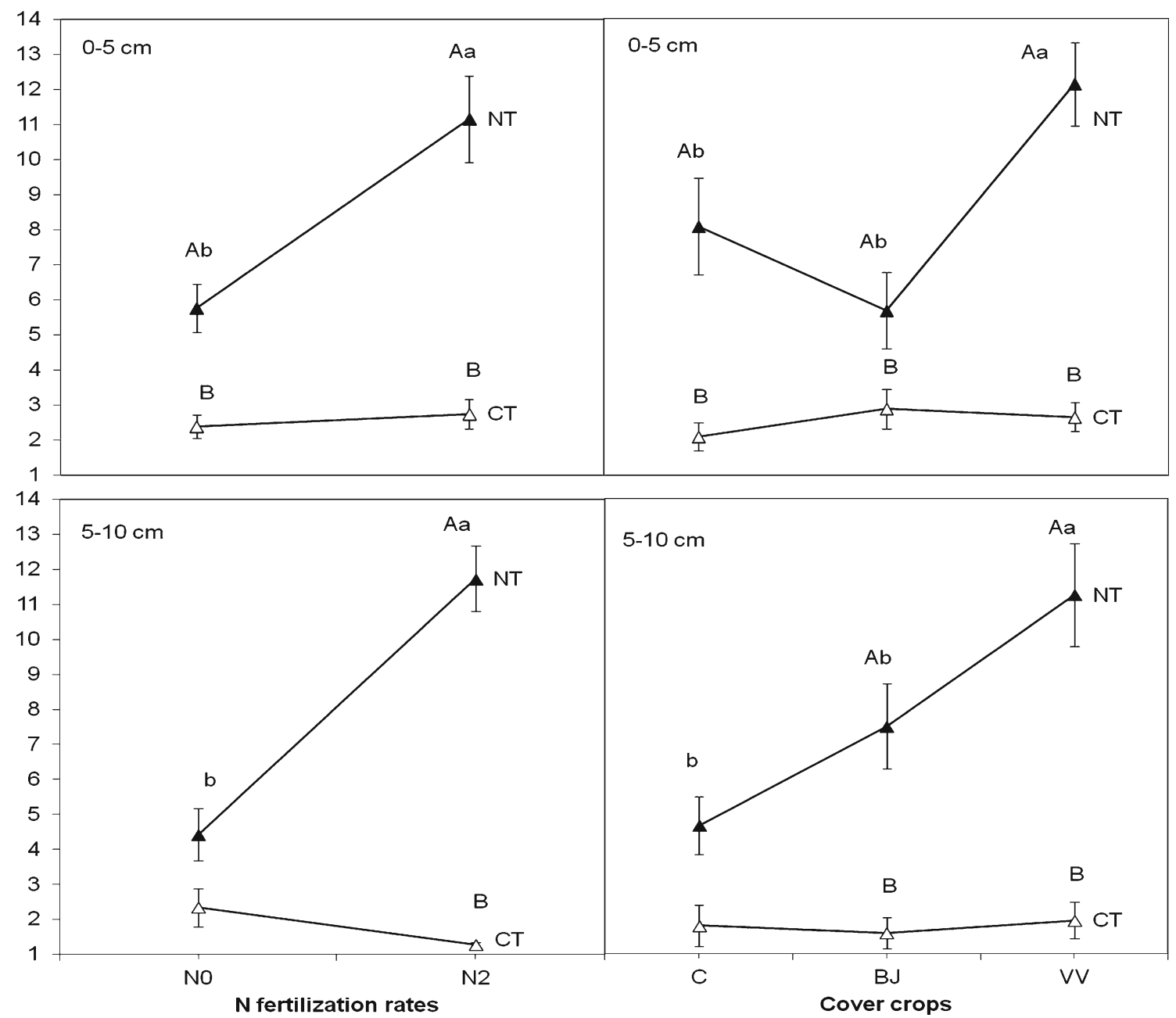

$\mathbf{N}$ fertilization rates

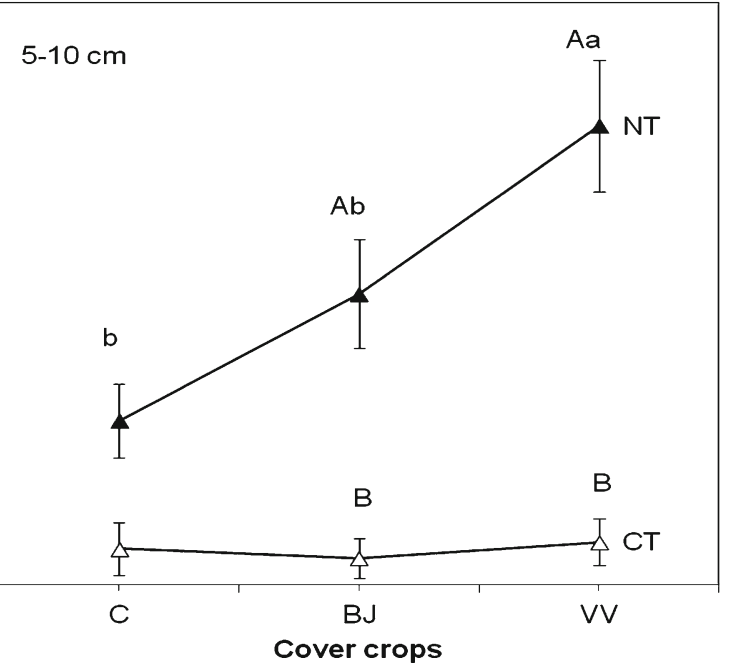

Fig. 2 Soil aggregate stability index (SASI) in the $0-5$ and $5-10 \mathrm{~cm}$ soil depths under no-tillage (NT) and conventional tillage (CT) systems as affected by two $\mathrm{N}$ fertilization rates $(\mathrm{N} 0=$ no $\mathrm{N}$ fertilization, $\mathrm{N} 2=$ medium $\mathrm{N}$ fertilization, see details in materials and methods) and three cover crops $(\mathrm{C}=$ no cover crops, $\mathrm{BJ}=B$. juncea and $\mathrm{VV}=V$. villosa $)$. Full and empty triangles represent NT and CT, respectively. The vertical bars are the standard errors of the mean. Means within the same tillage system

followed by the same lower case letter are not significantly influenced by $\mathrm{N}$ fertilization (on the left) or by cover type (on the right). Within the same $\mathrm{N}$ fertilization level (on the left) or the same cover type (on the right), significant effects of tillage is shown by different uppercase letters. $\mathrm{P}$ was always $<0.05$ (LSD test). The effects of $\mathrm{N}$ fertilization and $V$. villosa cover crops on the soil aggregate stability index were evident under NT but not under CT

the legume were not found to be significantly different from those of the other cover crops and the control.

The differences in soil organic matter content observed in the $10 \mathrm{~cm}$ top layer between the two tillage systems (Table 2) can be attributed to: (i) a different amount of crop residues returned to the soil because of the different biomass produced during the study; (ii) a different stratification of the litter in the soil layers; (iii) a different litter mineralization rate because of the different relievable conditions (oxygen availability, $\mathrm{pH}$, residues cutting and soil mixing, moisture, etc.). All these causes can act simultaneously and their effects are largely confirmed by the literature (e.g. Hazarika et al., 2009).

The previously published data (Mazzoncini et al., 2011) regarding the amount of organic matter returned to soil (crop residues plus weeds plus cover crops) highlighted that carbon inputs are on average higher in CT than NT systems: 7.73 vs $6.59 \mathrm{Mg} \mathrm{ha}^{-1} \mathrm{y}^{-1}$ of dry biomass, above all because of the higher crop yields revealed in the ploughed plots. Hence the differences observed in SOM content in the top layer are mainly related to a different mineralization rate of the organic matter. In fact, the SOM content in the $0-30 \mathrm{~cm}$ layer was still higher in the NT than in the CT systems (2.07 and $1.83 \%$ ) respectively; although by a narrower margin compared to the shallow soil layer (3.31 and $2.19 \%$ respectively), because of the larger concentration of crop residues in the surface of no-tillage plots (Mazzoncini et al., 2011).

The increases in SOM under $\mathrm{N}$ fertilization and the use of $V$. villosa cover crop were put in relation to the higher mean 
SOM $(\%)$

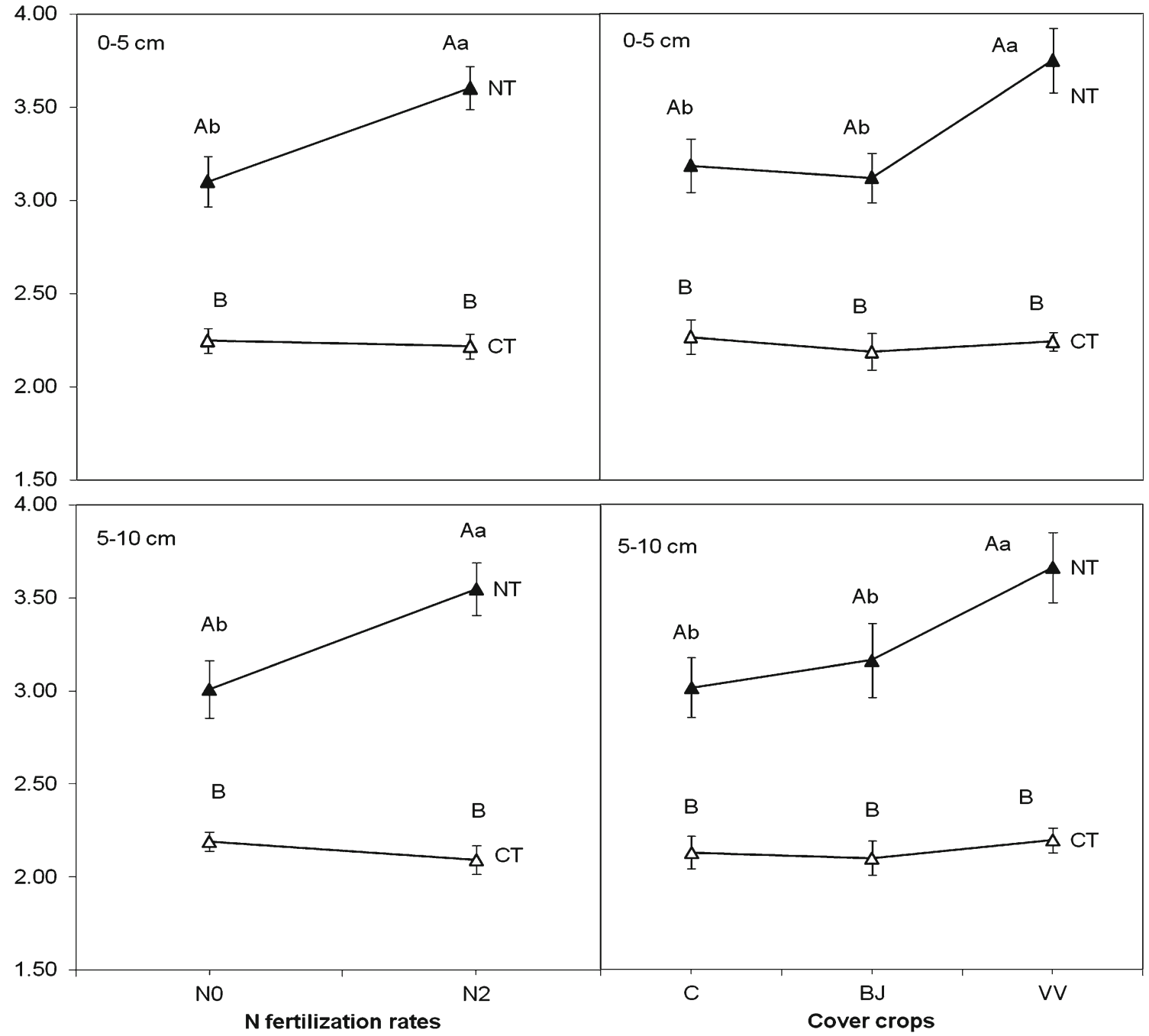

Fig. 3 Percentage of soil organic matter content (SOM) in 0-5 and 5$10 \mathrm{~cm}$ soil depth depths under no-tillage (NT) and conventional tillage (CT) systems as affected by two $\mathrm{N}$ fertilization rates $(\mathrm{N} 0=$ no $\mathrm{N}$ fertilization, $\mathrm{N} 2=$ medium $\mathrm{N}$ fertilization, see details in "Materials and methods" section) and three cover crops $(\mathrm{C}=$ no cover crops, $\mathrm{BJ}=B$. juncea and $\mathrm{VV}=V$. villosa). Full and empty triangles represent $\mathrm{NT}$ and $\mathrm{CT}$, respectively. Means within the same tillage system followed by the same lower

biomass returned to the soil: 5.34 and $7.82 \mathrm{Mg} \mathrm{ha}^{-1} \mathrm{y}^{-1}$ of dry biomass for non fertilized and fertilized treatments, respectively, and 5.74 and $8.11 \mathrm{Mg} \mathrm{ha}^{-1} \mathrm{y}^{-1}$ of dry biomass for the control and $V$. villosa cover crop, respectively.

The similarity of data trends with regard to soil organic matter and aggregate stability suggested the possible existence of a correlation between the two variables. The data analysis highlighted an exponential relationship indicating a more than proportional increase in soil aggregate stability as a result of the additional increment in soil organic matter content (Figure 4).

The increase in soil organic matter content explains the higher aggregate stability, which may be only partially case letter are not significantly influenced by $\mathrm{N}$ fertilization (on the left) or by cover type (on the right). Within the same $\mathrm{N}$ fertilization level (on the left) or the same cover type (on the right), significant effects of tillage is shown by different upper case letters. $P$ was always $<0.05$ (LSD test). The vertical bars are the standard errors of the mean. The effects of $\mathrm{N}$ fertilization and $V$. villosa cover crops on soil organic matter were evident under NT but not under CT

related to the effect of the reduced manipulation of soil due to no-tillage.

Many studies in different soil and climatic conditions have demonstrated a positive correlation between soil organic matter and the structural stability of soil aggregates (Cannell and Hawes, 1994; Mikha and Rice, 2004). Organic matter enables the soil aggregates to withstand rapid wetting and mechanical forces due to the use of tillage implements and to vehicular traffic (Tisdall and Oades, 1982). The organic matter also increases aggregate stability by lowering the wettability of soil aggregates and acting as a binding factor, thus increasing cohesion of the aggregates (Chenu et al., 2000). 
Soil Aggregate Stability Index

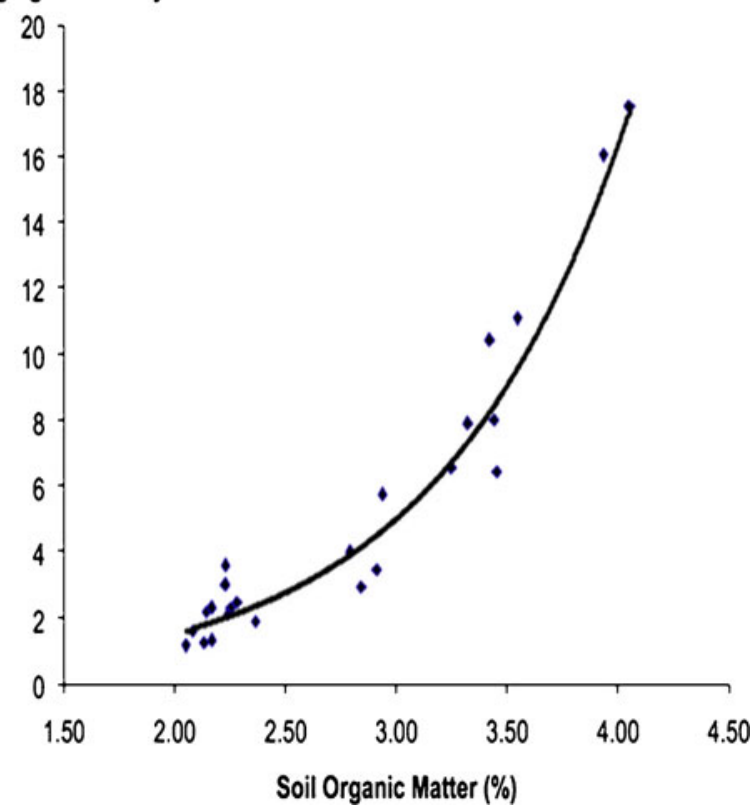

Fig. 4 Regression analysis between soil organic matter and soil aggregate stability index measured in $0-10 \mathrm{~cm}$ soil depth, $2008\left(\mathrm{y}=0.145 \mathrm{e}^{1.185 \mathrm{x}} ; \mathrm{R}^{2}=\right.$ $0.9041)$. Increased soil organic matter improved the stability of aggregates probably due to its binding effects on soil structure

The tillage systems adopted significantly affected soil bulk density in all soil depths (Table 3). In agreement with Pedrotti et al. (2005), the NT system had a lower bulk density than the CT system in the top layer $(0-10 \mathrm{~cm})$, however the bulk density below $10 \mathrm{~cm}$ soil layers was higher in the NT system than the CT system. N fertilization and interaction effects were not significant for bulk density in none of the soil depths. Soil cover types affected bulk density significantly in the $10-20 \mathrm{~cm}$ soil depth, but not in other layers. None of the interaction effects were significant.

The decrease in bulk density in the top layer under the NT system can be explained by the corresponding increase in soil organic matter content (Cannell and Hawes, 1994; Reicosky et al., 1995; Hazarika et al., 2009) and structure stability, which preserves the soil layer by sealing phenomena that are potentially able to reduce soil porosity. Lower bulk density in the upper $10 \mathrm{~cm}$ of soil under NT may also be related to the protective function of crop residues left on the soil surface against disaggregating rainfall. This may also be the reason for the smaller bulk density values observed in the top layer with the cover crop cultivation.

\subsection{Soil microbiological parameters}

The tillage systems significantly affected the soil microbial C content and respiration, but not the metabolic or microbial quotients. The higher amount of $\mathrm{CO}_{2}$ respired and the larger microbe biomass revealed in the NT systems were a consequence of the greater soil organic matter content. However neither the microbial abundance, nor the microbial activity were significantly different from the CT systems.

Soil microbial respiration and soil microbial $\mathrm{C}$ content were about 80 and $70 \%$ higher respectively in the NT system than in the CT system (Table 4). $\mathrm{N}$ fertilization and cover crop management did not significantly affect the soil microbiological parameters tested in this research. None of the interaction effects were significant except Nitrogen fertilization $\mathrm{x}$ Tillage for soil microbial respiration and metabolic quotient. $\mathrm{N}$ fertilization increased the soil microbial respiration under CT but slightly decreased it under NT. Nitrogen fertilization increased the microbial quotient in $\mathrm{CT}$, whereas it decreased in NT.

The increments in soil microbial $\mathrm{C}$ content and respiration under NT system were consistent with many previous findings (e.g. Hazarika et al., 2009; Hungria et al., 2009). Increased microbial activity under NT can be attributed, in addition to higher SOM content, to several factors, such as, better soil aggregation, a lower temperature and higher moisture content (Balota et al., 2003). The lack of disturbance in the NT system
Table 3 Effect of tillage systems, $\mathrm{N}$ fertilization and cover crops on soil bulk density across different soil depths, 2008. Within each factor, means in the same column followed by different letters are significantly different at $\mathrm{P}<0.05$

(LSD test). ${ }^{\star} \mathrm{CT}$ is conventional tillage and NT is no tillage. ${ }^{\S} \mathrm{N} 0=\mathrm{No} \mathrm{N}$ fertilization, $\mathrm{N} 2=200,120$ and $100 \mathrm{~kg} \mathrm{Nha}^{-1}$ for maize, durum wheat and sunflower, respectively. ${ }^{\top} \mathrm{C}$, no cover crops; BJ, $B$. juncea; $\mathrm{VV}, V$. villosa

\begin{tabular}{|c|c|c|c|c|}
\hline \multirow[t]{2}{*}{ Treatments } & \multicolumn{4}{|c|}{ Bulk Density $\left(\mathrm{g} \mathrm{cm}^{-3}\right)$ at depth $(\mathrm{cm})$} \\
\hline & $0-10$ & $10-20$ & $20-30$ & $0-30$ \\
\hline \multicolumn{5}{|l|}{ Tillage } \\
\hline NT & $1.37 \mathrm{~b}$ & $1.51 \mathrm{a}$ & $1.54 \mathrm{a}$ & $1.48 \mathrm{a}$ \\
\hline $\mathrm{CT}$ & $1.41 \mathrm{a}$ & $1.44 \mathrm{~b}$ & $1.43 \mathrm{~b}$ & $1.43 \mathrm{~b}$ \\
\hline \multicolumn{5}{|c|}{$\mathrm{N}$ fertilization ${ }^{\S}$} \\
\hline No & 1.40 & 1.47 & 1.48 & 1.45 \\
\hline $\mathrm{N} 2$ & 1.38 & 1.48 & 1.49 & 1.45 \\
\hline \multicolumn{5}{|c|}{ Cover Crops ${ }^{\S}$} \\
\hline $\mathrm{C}$ & 1.40 & $1.47 \mathrm{ab}$ & 1.48 & 1.45 \\
\hline $\mathrm{BJ}$ & 1.39 & $1.49 \mathrm{a}$ & 1.48 & 1.46 \\
\hline VV & 1.38 & $1.46 \mathrm{~b}$ & 1.50 & 1.45 \\
\hline
\end{tabular}


Table 4 Effects of tillage systems, $\mathrm{N}$ fertilization and cover crops on soil microbial respiration (SMR), microbial Carbon $\left(\mathrm{C}_{\mathrm{mic}}\right)$, metabolic quotient $\left(\mathrm{qCO}_{2}\right)$ and microbial quotient $\left(\mathrm{C}_{\text {mic }} / \mathrm{C}_{\text {org }}\right)$ at $0-10 \mathrm{~cm}$ depth. Within each factor, means in the same column followed by different letters are significantly different at $\mathrm{P}<0.05$ (LSD test). ${ }^{\ddagger} \mathrm{CT}$, conventional tillage and $\mathrm{NT}$, no tillage. ${ }^{\S} \mathrm{N} 0=$ no $\mathrm{N}$ fertilization, $\mathrm{N} 2=200,120$ and $100 \mathrm{~kg} \mathrm{Nha}^{-1}$ for maize, durum wheat and sunflower, respectively. ${ }^{\top} \mathrm{C}$, no cover crops; $\mathrm{VV}$, V. villosa. $*$ is significant at 0.05 probability level. NS is not significant

\begin{tabular}{|c|c|c|c|c|}
\hline Treatments & $\operatorname{SMR}\left(\mu \mathrm{g} \mathrm{CO} \mathrm{g}^{-1} \mathrm{~h}^{-1}\right)$ & $\mathrm{C}_{\text {mic }}\left(\mu \mathrm{g} \mathrm{Cg}{ }^{-1}\right.$ soil $)$ & $\mathrm{qCO}_{2}$ & $\mathrm{C}_{\text {mic }}: \mathrm{C}_{\text {org }}$ ratio $\left(\mathrm{mg} \mathrm{C}_{\text {mic }} \mathrm{g}^{-1} \mathrm{C}_{\text {org }}\right)$ \\
\hline \multicolumn{5}{|l|}{ Tillage $(T)^{\ddagger}$} \\
\hline NT & $5.16 \mathrm{a}$ & 570.7 a & 112.0 & 32.57 \\
\hline $\mathrm{CT}$ & $2.90 \mathrm{~b}$ & $333.6 \mathrm{~b}$ & 115.2 & 25.25 \\
\hline \multicolumn{5}{|c|}{$\mathrm{N}$ fertilization $(\mathrm{N})^{\S}$} \\
\hline N0 & 3.91 & 435.4 & 112.2 & 26.90 \\
\hline $\mathrm{N} 2$ & 4.15 & 468.9 & 115.0 & 28.92 \\
\hline \multicolumn{5}{|c|}{ Cover Crops $(\mathrm{C})^{\pi}$} \\
\hline $\mathrm{C}$ & 3.99 & 429.6 & 110.3 & 28.19 \\
\hline VV & 4.07 & 474.7 & 116.9 & 27.62 \\
\hline
\end{tabular}

Individuals sample-1

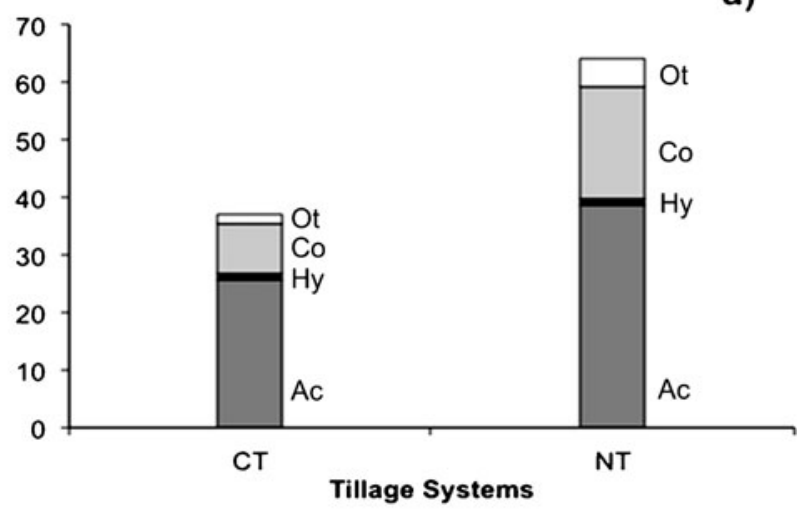

Individuals sample-1

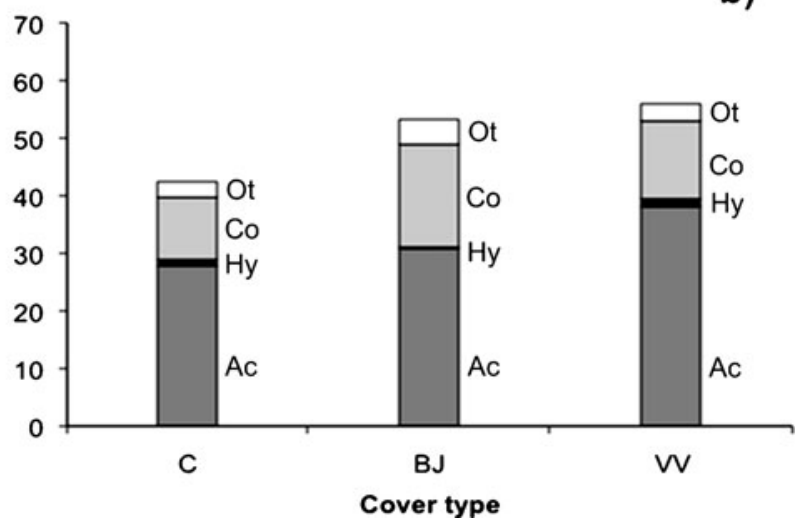

Fig. 5 Major taxa of micro-arthropods and associated number of individuals: $\mathbf{a}$ under two tillage systems $(\mathrm{CT}=$ conventional tillage, $\mathrm{NT}=$ no tillage, $\mathrm{n}=12)$; and $\mathbf{b}$ under three cover types $(\mathrm{C}=$ no cover crops, $\mathrm{BJ}=B$. juncea and $\mathrm{VV}=V$. villosa) systems. Ac (dark grey bars) $=$ Acari; Hy (black bars) $=$ Hymenoptera Co (light grey bars) $=$ Collembola; Ot (white bars $)=$ other micro-arthropods. NT systems and all the systems planted to cover crops show tendency to have higher number of individuals under most of the taxa as compared with conventional tillage system and the system without cover crops, respectively provides a steady source of organic $\mathrm{C}$ to support the microbial community as compared to the CT system where each tillage event increases the temporary flush of microbial activity resulting in large losses of carbon as $\mathrm{CO}_{2}$ (Reicosky et al., 1995).

\subsection{Biological parameters}

Irrespective of the treatments, Acari was the most abundant micro-arthropod group found in the study site, followed by Collembola and Hymenoptera (Figure 5). Other microarthropod groups such as Isopoda, Symphyla, Coleoptera, Diplura, Chilopoda, Diplopoda and Pauropoda, were only observed in some samples but not all of them.

The effect of the tillage system was significant for Simpson's diversity index and the richness of the micro-arthropod groups, but not for group evenness. Simpson's index was about $40 \%$ higher in the NT system than in the CT system (Table 5). The effect of the cover crops was significant in terms of the abundance (i.e. richness) of micro-arthropod groups. On average,

Table 5 Effect of tillage and cover crops on soil biological quality measured as BSQ index and micro-arthropod diversity (Simpson's D), richness and evenness (2008). Within each factor, means in the same column followed by different letters are significantly different at $\mathrm{P}<0.05$ (LSD test). NS, non significant. ${ }^{\star} \mathrm{CT}$, conventional tillage, NT, no tillage. ${ }^{\S} \mathrm{C}$, no cover crop; BJ, B. juncea, VV, V. villosa

\begin{tabular}{lcccc}
\hline Treatments & BSQ value & Simpson's D & Richness & Evenness \\
\hline Tillage $(\mathrm{T})^{\ddagger}$ & & & & \\
NT & $75.0 \mathrm{a}$ & $2.58 \mathrm{a}$ & $6.17 \mathrm{a}$ & 0.41 \\
$\mathrm{CT}$ & $43.3 \mathrm{~b}$ & $1.88 \mathrm{~b}$ & $4.08 \mathrm{~b}$ & 0.40 \\
Cover Crops $(\mathrm{C})^{\S}$ & & & \\
C & $49.5 \mathrm{~b}$ & 2.03 & $4.25 \mathrm{~b}$ & 0.43 \\
BJ & $61.1 \mathrm{ab}$ & 2.24 & $5.63 \mathrm{a}$ & 0.41 \\
VV & $66.9 \mathrm{a}$ & 2.41 & $5.50 \mathrm{a}$ & 0.38 \\
\hline
\end{tabular}


the system planted with cover crops increased the richness by $30 \%$ and the diversity index by $15 \%$ compared to the system without cover crops (Table 5).

The tillage system and cover crops significantly affected the biological soil quality index value, which was $73 \%$ higher in the NT than in the CT (Table 5). The systems grown with the $V$. villosa cover crop had a $35 \%$ higher value than the system without a cover crop. The interaction effect of tillage and cover crops was not significant for biological soil quality index.

In the NT systems, surface residues provide food supplies for micro-arthropods, physical protection for shallowsurface dwelling and serve as mulch, thus slowing down the rate of soil desiccation in spring/summer and soil freezing in winter. Increased numbers and the biomass of mesoand macro-fauna in soil under NT management have also been reported from different parts of the world (e.g. Paoletti et al., 1991; Wardle, 1995).

The biological soil quality index values found in our research are within the range reported in studies conducted in arable cropping systems (e.g. Parisi et al., 2005).

The presence of groups with a higher eco-morphological index such as Symphyla, Diplopoda and Coleoptera larvae in the NT system was the main reason for the higher biological soil quality index compared to the CT system.

The increased diversity of micro-arthropod groups and the higher biological soil quality value in the plots where cover crops were included (Table 5) was likely due to the increased amount of biomass produced in these systems. This might have improved the micro-climate as well as the food resources for different groups of micro-arthropods, thereby increasing their numbers, diversity and thus the biological value.

\section{Conclusions}

Compared to conventional tillage systems, no-tillage systems increased soil organic matter and soil aggregate stability, and improved bulk density in the top layer and also several important biological characteristics. The beneficial effects of $\mathrm{N}$ fertilization and cover cropping were more evident on soil organic matter, aggregate stability and biological soil characteristics, however their efficacy depended on the adoption of an agronomic strategy including notillage techniques.

In the experimental conditions, the adoption of NT and the inclusion of $V$. villos $a$ as a cover crop in the arable crop rotation, together with the use of a moderate rate of $\mathrm{N}$ fertilization provided the best strategy to obtain better physical and chemical soil properties and improve the pedofauna biodiversity.

The use of biological indicators seemed to provide similar indications as those inferred from other parameters, thus confirming their utility in soil ecosystem assessments.
The improvement in all the soil indicators however, did not lead to a corresponding increase in crop productivity; the mean values of biomass production throughout the study period showed that the conventional tillage systems gave higher yields than the no-tillage systems. The reasons for these discrepancies were related to the temporary establishment in the no-tillage systems of unfavourable conditions for crop growth i.e. stagnant soil water (autumn-winter) and incomplete restoration of water capacity (spring-summer), which cannot be highlighted using a one-step monitoring design. Hence the short-term interactions between the soil and crops can counteract the improvement in soil characteristics achieved as a result of long-lasting repeated management practices. This thus highlights the importance of environmental conditions (i.e. soil type, rainfall and distribution) in the performance of cropping systems.

Acknowledgements We would like to thank the field staff of CIRAA for their assistance in the soil sampling, together with Giulia Carpi, Sabrina Ciampa and Nathaly Castro Rodas for their technical assistance in the laboratory analysis.

\section{References}

Alef K (1995) Soil Respiration. In: Alef K, Nannipieri P (eds) Methods in Applied Soil Microbiology and Biochemistry. Academic Press Limited, London, pp 214-219

Alvarez R, Steinbach HS (2009) A review of the effects of tillage systems on some soil physical properties, water content, nitrate availability and crops yield in the Argentine Pampas. Soil \& Tillage Research 104:1-15

Balota EL, Colozzi-Filho A, Andrade DS, Dick RP (2003) Microbial biomass in soils under different tillage and crop rotation systems. Biology and Fertility of Soils 38:15-20

Cambardella CA, Elliott ET (1993) Carbon and Nitrogen Distribution in Aggregates from Cultivated and Native Grassland Soils. Soil Science Society of America Journal 57:1071-1076

Cannell RQ, Hawes JD (1994) Trends in tillage practices in relation to sustainable crop production with special reference to temperate climates. Soil \& Tillage Research 30:245-282

Chenu C, Bissonnais YL, Arrouays D (2000) Organic matter influence on clay wettability and soil aggregate stability. Soil Science Society of America Journal 64:1479-1486

CoHort S (2002) CoStat Software. www.cohort.com, Monterey, California, USA

Dabney SM, Delgado JA, Reeves DW (2001) Using winter cover crops to improve soil and water quality. Communications in Soil Science and Plant Analysis 32(7):1221-1250

De Goede RGM, Brussaard L (2002) Soil zoology: An indispensable component of integrated ecosystem studies. European Journal of Soil Biology 38(1):1-6

Gomez K, Gomez A (1984) Statistical procedures for agricultural research. John Wiley \& Sons, New York, USA

Hao X, Ball BC, Culley JLB, Carter MR, Parkin GW (2006) Soil Density and Porosity, in: M.R. Carter, E.G. Gregorich (Eds.), Soil Sampling and Method of Analysis, Canadian Society of Soil Science

Hazarika S, Parkinson R, Bol R, Dixon L, Russell P, Donovan S, Allen D (2009) Effect of tillage system and straw management on 
organic matter dynamics. Agronomy for Sustainable Development 29(4):525-533

Hungria M, Franchini JC, Brandao-Junior O, Kaskhuk G, Souza RA (2009) Soil microbial activity and crop sustainability in a longterm experiment with thre soil-tillage and two crop-rotation systems. Applied Soil Ecology 42:288-296

Kemper WD, Rosenau RC (1986) Aggegate stability and size distribution. In: Klute A (ed) Methods of Soil Analysis, Part I. Soil Science Socity of America, Madison, WI, pp 425-442

Kladivko EJ, Griffith DR, Mannering JV (1986) Conservation tillage effects on soil properties and yield for corn and soybeans in Indiana. Soil \& Tillage Research 8:277-287

Lal R (2004) Soil carbon sequestration to mitigate climate change. Geoderma 123:1-22

Magurran AE (2004) Measuring biological diversity. Blackwell publishing Company ISBN-31:978-0-632-05633-0

Malhi SS, Lemke R (2007) Tillage, crop residue and N fertilizer effects on crop yield, nutrient uptake, soil quality and nitrous oxide gas emissions in a second 4-yr rotation cycle. Soil \& Tillage Research 96:269-283

Mazzoncini M, Sapkota TB, Bàrberi P, Antichi D, Risaliti R (2011) Long-term effect of tillage, nitrogen fertilization and cover crops on soil organic carbon and total nitrogen content. Soil and Tillage Research 114(2):165-174

Mikha MM, Rice CW (2004) Tillage and manure effects on soil and aggregate-associated carbon and nitrogen soil. Science Society of America Journal 68:809-816

Nelson DW, Sommers LE (1982) Total Carbon, Organic Carbon and Organic Matter. In: Page AL (ed) Methods of Soil Analysis, Part 2, American Society of Agronomy, Soil Science Society of America. Publisher, Madison, Wisconsin, USA, Inc, pp 539-579
Pagliai M, Torri D, Patruno A (1997) Stabilità e distribuzione dimensionale degli aggregati. Cap. V. In : Metodi di analisi fisica del suolo. Ed. Franco Angeli

Paoletti MG, Favretto MR, Stinner BR, Purrington FF, Bater JE (1991) Invertebrates as bioindicators of soil use. Agriculture Ecosystems \& Environment 34:341-362

Parisi V, Menta C, Gardi C, Jacomini C, Mozzanica E (2005) Microarthropod communities as a tool to assess soil quality and biodiversity: a new approach in Italy. Agriculture, Ecosystems and Environment 105:323-333

Pedrotti A, Pauletto EA, Crestana S, Holanda FSR, Cruvinel PE, Vaz CMP (2005) Evaluation of bulk density of Albaqualf soil under different tillage systems using the volumetric ring and computerized tomography methods. Soil \& Tillage Research 80:115-123

Reicosky DC, Kemper WD, Langdale GW, Douglas Jr CL, Rasmussen PE (1995) Soil organic matter changes resulting from tillage and biomass production, J.Soil Water Conserv, 253-261

Silvestri N, Bellocchi G (2007) Designing sustainable cropping systems: a general framework. In: Farming Systems Design 2007, Int. Symposium on Methodologies on Integrated Analysis on Farm production Systems, 119-120. La Goliardica Pavese s.r.1., Pavia (IT).

Tisdall JM, Oades JM (1982) Organic matter and water-stable aggregates in soils. Journal of Soil Science 33:141-163

Vance ED, Brookes PC, Jenkinson DS (1987) An extraction method for measuring soil microbial biomass C. Soil Biology \& Biochemistry 6:703-770

Wardle DA (1995) Impacts of disturbance on detritus food webs in agro-ecosystems of constrasting tillage and weed management practices. In: Begon M, Fitter AH (eds) Advances in Ecological Research. Academic, New York, pp 105-185 